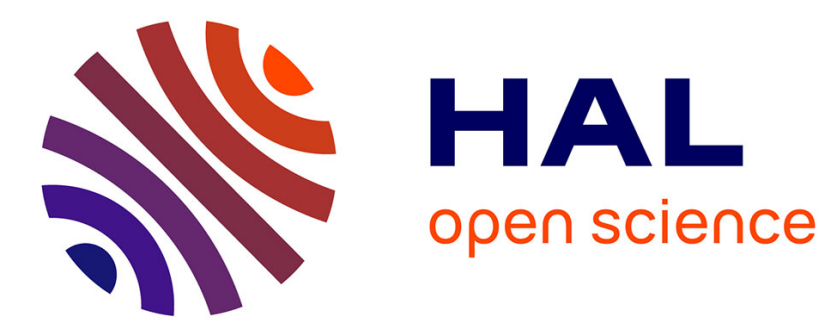

\title{
Cyclic tensile machine with wide speed range for in situ neutron/X-ray scattering study on elastomers
}

Nan Tian, Tingting Wang, Xiaoqing Tu, Yue Shui, Jianzhu Ju, Guangai Sun, Dong Liu

\section{> To cite this version:}

Nan Tian, Tingting Wang, Xiaoqing Tu, Yue Shui, Jianzhu Ju, et al.. Cyclic tensile machine with wide speed range for in situ neutron/X-ray scattering study on elastomers. Review of Scientific Instruments, 2020, 91 (1), pp.015113. 10.1063/1.5128047 . hal-02503263

\section{HAL Id: hal-02503263 \\ https://hal.science/hal-02503263}

Submitted on 9 Mar 2020

HAL is a multi-disciplinary open access archive for the deposit and dissemination of scientific research documents, whether they are published or not. The documents may come from teaching and research institutions in France or abroad, or from public or private research centers.
L'archive ouverte pluridisciplinaire HAL, est destinée au dépôt et à la diffusion de documents scientifiques de niveau recherche, publiés ou non, émanant des établissements d'enseignement et de recherche français ou étrangers, des laboratoires publics ou privés. 


\section{Cyclic tensile machine with wide speed range for in situ neutron/X-ray scattering study on elastomers}

Cite as: Rev. Sci. Instrum. 91, 015113 (2020); https://doi.org/10.1063/1.5128047

Submitted: 16 September 2019 . Accepted: 29 December 2019 . Published Online: 17 January 2020

Nan Tian (D), Tingting Wang, Xiaoqing Tu, Yue Shui, Jianzhu Ju, Guangai Sun, and Dong Liu
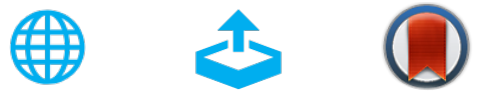

View Online

Export Citation

\section{ARTICLES YOU MAY BE INTERESTED IN}

Development of a reactor for the in situ monitoring of 2D materials growth on liquid metal catalysts, using synchrotron x-ray scattering, Raman spectroscopy, and optical microscopy Review of Scientific Instruments 91, 013907 (2020); https://doi.org/10.1063/1.5110656

A novel high power vacuum diode with a focusing electrode for effective operation in a low guiding magnetic field

Review of Scientific Instruments 91, 014706 (2020); https://doi.org/10.1063/1.5126691

Compact circular polarizer based on cross-shaped slot for high-power microwave applications

Review of Scientific Instruments 91, 014707 (2020); https://doi.org/10.1063/1.5140258

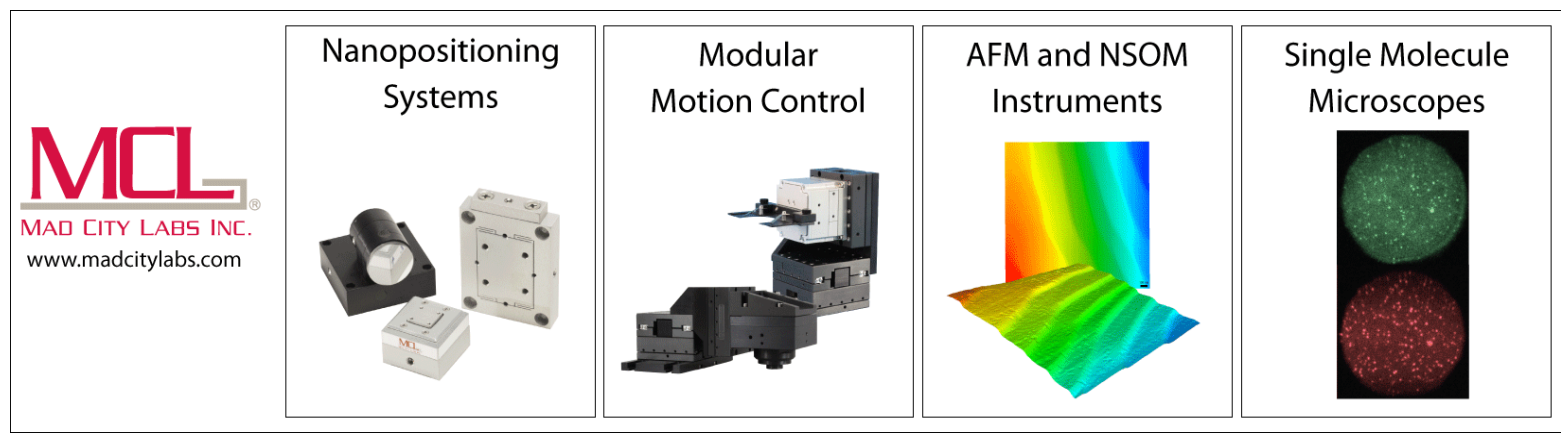




\title{
Cyclic tensile machine with wide speed range for in situ neutron/X-ray scattering study on elastomers
}

\author{
Cite as: Rev. Sci. Instrum. 91, 015113 (2020); doi: 10.1063/1.5128047 \\ Submitted: 16 September 2019 - Accepted: 29 December 2019 • \\ Published Online: 17 January 2020
}

\begin{abstract}
Nan Tian, ${ }^{1, a)}$ (D) Tingting Wang, ${ }^{2}$ Xiaoqing Tu, ${ }^{2}$ Yue Shui, ${ }^{2}$ Jianzhu Ju, ${ }^{3, a)}$ Guangai Sun, ${ }^{2}$ and Dong Liu
AFFILIATIONS

${ }^{1}$ MOE Key Laboratory of Space Applied Physics and Chemistry, Shaanxi Key Laboratory of Macromolecular Science and Technology, School of Science, Northwestern Polytechnical University, Xi'an 710072, People's Republic of China

${ }^{2}$ Key Laboratory of Neutron Physics and Institute of Nuclear Physics and Chemistry, China Academy of Engineering Physics, 621999 Mianyang, China

${ }^{3}$ Laboratoire Sciences et Ingénierie de la Matière Molle, ESPCI Paris, PSL University, CNRS, Sorbonne Université, 75005 Paris, France
\end{abstract}

\begin{abstract}
a) Authors to whom correspondence should be addressed: tiannan@nwpu.edu.cn; jianzhu.ju@espci.fr; and dongliu10@mail.ustc.edu.cn
\end{abstract}

\begin{abstract}
A tensile machine is designed for in situ scattering investigation of elastomers in the cyclic tensile process. The specimen is stretched by two linearly moving clamps in the opposite direction; thus, the center of the specimen is kept stationary during the tensile test. With this configuration, either X-ray scattering or neutron scattering can be carried out easily. A high speed direct current motor is used to drive the machine, providing a wide tensile speed range from $1.28 \times 10^{-3} \mathrm{~mm} / \mathrm{s}$ to $102.4 \mathrm{~mm} / \mathrm{s}$. Cyclic tension is achieved by program controlled motor rotation, and the engineering stress-strain curve can be saved automatically in each cycle. Moreover, an independent displacement sensor is used to check the possible accumulative error of position during cyclic tension. The orientation change of multiwall carbon nanotube filled silicon rubber is investigated by small angle neutron scattering to test the machine, which shows that the machine is capable of combining the cyclic tensile test with in situ scattering measurement.
\end{abstract}

Published under license by AIP Publishing. https://doi.org/10.1063/1.5128047

\section{INTRODUCTION}

Elastomers, e.g., natural rubber, thermoplastic polyurethane, and gel, are widely used in various fields for their ability to bear large recoverable deformation. In practical use, it is found that the structure and subsequent mechanical response change with the imposed deformation. For example, natural rubber will crystallize at an elongation ratio of around 4, which leads to significant strain hardening and reinforcement of the material. ${ }^{1,2}$ While for double-network gels, the crosslinking network may be partially destroyed at large deformation. $^{3-7}$ The changes in the structure result in significant hysteresis in the stress-strain curve. ${ }^{5,8,9}$ In other words, the stress response is not the same in different cycles of loading and often irreversible deformation exists. ${ }^{10,11}$ Moreover, segments in the nonideal network of elastomers relax at different time scales, giving rise to a stress response with significant strain rate-dependence. ${ }^{12-15}$ To evaluate the performance of elastomers comprehensively, information about both the structural change and stress response during deformation and recovery is needed, especially in cases when cyclic deformation happens. Under this condition, an apparatus that enables cyclic tension, in situ structure characterization, and varied strain rate is required.

Several tensile machines are commercially available, which partially meet these requirements. The most commonly used one is the universal testing system from Instron, e.g., the compact Instron $3342 .{ }^{16,17}$ In this system, one clamp is fixed and the other one moves with constant speed. The test space is up to $651 \mathrm{~mm}$, which is large enough for a broad specimen size. In this respect, the system 
is indeed universal for mechanical measurement. Nevertheless, the design that only one clamp moves makes scattering investigations difficult. For scattering measurement, the detecting point is usually fixed at the center of the specimen during tension, and typically, the position of the incident beam is fixed. It means that the center of the specimen should be fixed during tension, which can hardly be satisfied by using Instron 3342. To overcome this problem, Instron developed a tensile machine using two symmetric actuators, which can move independently in the opposite direction. ${ }^{18}$ When the speed of actuators is set the same, this machine is capable of carrying out scattering experiments. However, as a custom-built machine, it is still not widely available at present. The condition is better for other tensile testing stages designed for in situ characterization. For example, in the widely used TST350 tensile stage (Linkam, UK), two clamps move oppositely. ${ }^{19,20}$ The maximum distance of tension is $80 \mathrm{~mm}$ when the minimal specimen length $26 \mathrm{~mm}$ is used. This stage has been frequently used in in situ X-ray scattering measurement. However, the rather small hole permitting the beam to pass through makes it difficult to carry out neutron scattering investigation. The stage from Deben (UK) is similar to TST350, but the size is even smaller to combine with the scanning electronic microscope. The tensile distance of this stage is reduced to $20 \mathrm{~mm}$, restricted by its small size. These two stages are capable of conducting stress and X-ray scattering measurement simultaneously. However, program controlled cyclic tension is commonly unavailable to the best of our knowledge. In addition, these two machines cannot be combined with neutron scattering at present, which is a powerful tool for composite materials. $^{21-24}$

Besides commercial tensile machines emphasizing universality, laboratory machines for different applications have also been developed. Cakmak's group has first successfully combined real time birefringence measurement with the tensile machine. ${ }^{25,26}$ Based on the stress-optical law, chain orientation during tension can be precisely obtained. Kinds of transparent materials, e.g., rubber, ${ }^{26}$ poly(amide-imide) film, ${ }^{27}$ and Nylon $\mathrm{MXD}^{28},{ }^{28}$ have been investigated. More recently, stress softening of the natural rubber/clay nanocomposite during cyclic stretching and retraction is also studied with this machine, revealing complex changes of chain orientation during both extension and retraction. ${ }^{29}$ Li's group developed a series of tensile machines covering uniaxial tension of solid, ${ }^{30,31}$ melt stretching, ${ }^{32-34}$ and also biaxial film stretching. ${ }^{31}$ Synchrotron radiation X-ray scattering is commonly used to detect structural evolution, which provides good time resolution and does not require a transparent sample. By using the machine providing Hencky strain, strain-induced crystallization of natural rubber is investigated. ${ }^{34}$ The result indicates that strain-induced crystallization has a close relation with strong strain-hardening in the stress-strain curve.

Furthermore, most tensile stages mentioned above focus on low-speed tension. For solid with a relatively small break strain or yield strain, it is necessary to lower the tensile speed to increase strain resolution. While for elastomers, no yield happens during tension and the break strain can easily exceed $100 \%$. Moreover, the crosslinking network of elastomers is commonly not ideal. Dangling chains, loops, and regions with different crosslinking densities may coexist, ${ }^{13,35,36}$ which leads to a rate-dependent stress response. The dependence may be more significant in gels, in which the solvent can be squeezed out during tension. ${ }^{37,38}$ Under this condition, the tensile speed may be required to vary in a large range. Even though commercial fatigue testing machine can provide cyclic tension with a frequency up to $100 \mathrm{~Hz}$, the strain is usually small. ${ }^{39,40}$ A custombuilt tensile machine enabling large tensile speed, strain, and high cyclic frequency has been reported, ${ }^{41}$ while it is not widely available. Till now, few results about tensile testing of the elastomer in a wide speed range have been reported partially because no commercial tensile machine is available.

To solve the problem, a new tensile machine which enables simultaneous in situ X-ray or neutron scattering measurement and cyclic tension was developed. The tensile speed can vary in nearly five orders of magnitude. As a demonstration, the in situ small angle neutron scattering (SANS) experiment was carried out during cyclic tension of carbon nanotube filled silicon rubber.

\section{TENSILE MACHINE}

\section{A. Demonstration of the mechanical design}

The design of the tensile machine is demonstrated in Fig. 1(a). A high-precision servo motor (Maxon, Switzerland) is used to drive the machine. Rotation of the motor is transformed into linear movement by using bidirectional ball screw shafts (BSS). Additionally, two guide shafts are mounted parallelly with BSS to assure the linearity during extension, especially under a high tensile force. Sliders on each shaft are connected by using the connecting plate, which constitutes two sliding units (SU1 and SU2). The force sensor mounted on SU1 measures the stress change during tension. Clamps fixing the specimen are placed in the heating chamber so that heating of the whole sample can be achieved during the tensile test. For the sake of scattering investigation, two sets of switchable windows that allow

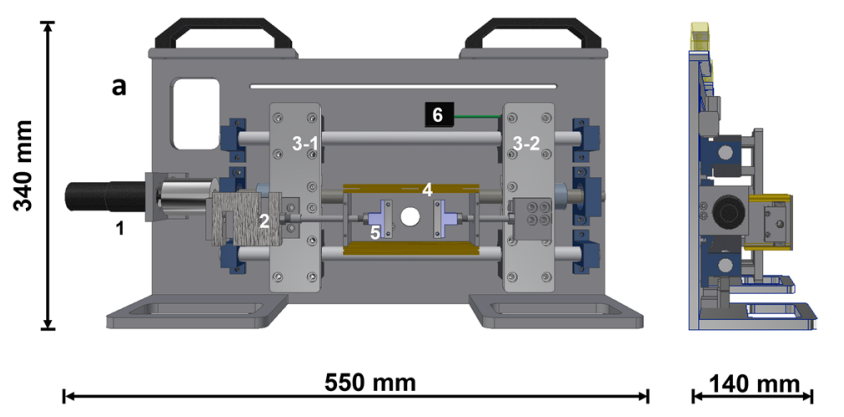

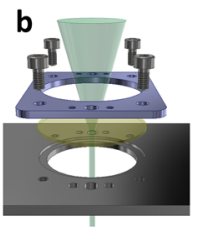

FIG. 1. (a) Schematic drawing of the tensile machine. Components are indicated: 1. Servo motor. 2. Force sensor 3. Sliding units (SU), including ball screw shaft, guide shaft, slider, and connecting plate. 4. Heating chamber. 5. Dismountable clamps. 6. Displacement sensor. (b) Replaceable window for $\mathrm{X}$-ray/neutron scattering. 
the incident and scattered X-ray/neutron beams to pass through are designed, as shown in Fig. 1(b). The center of the heating chamber is designed to be $10 \mathrm{~mm}$ away from the edge of BSS, considering that the typically chosen diameter of the neutron beam of the SANS-Suanni spectrometer ${ }^{42-44}$ at China Mianyang Research Reactor $^{45}$ (CMRR) is $8 \mathrm{~mm}$. A displacement sensor is used to detect the position of SU2, which can easily indicate possible errors of position after cyclic tension.

The technical parameters are summarized in Table I.

\section{B. The mechanical part}

The servo motor from Maxon is selected to drive the machine, which can rotate at a maximum speed of 10000 revolutions per minute (rpm) continuously. The high speed ensures a large range of tensile speed. For the sake of precise control, it is equipped with an encoder giving 65536 counts per turn and a gearbox with a reduction of $26: 1$. The maximum input of this gearbox is $8000 \mathrm{rpm}$; thus, the maximum output speed of this system is $307.6 \mathrm{rpm}$ according to the following equation, where $n_{\text {out }}, n_{i n}$, and $i$ are the output speed, input speed, and reduction of the gear box, respectively:

$$
n_{\text {out }}=n_{\text {in }} / i \text {. }
$$

Rotation of the motor is transformed into linear movement of SU by coupling the connected BSS. The linear speed also depends on the lead of BSS, which indicates the distance SU moves when BSS rotates one turn. In this work, the lead of BSS is $10 \mathrm{~mm}$. The maximum speed can be obtained by using the following equation:

$$
v=n_{\text {out }} \times l,
$$

where $v$ is the linear speed of the clamp and $l$ is the lead of BSS. Since two SUs move simultaneously, the actual maximum tensile speed is $2 v=102.4 \mathrm{~mm} / \mathrm{s}$. Similarly, the minimum speed is determined by the lowest speed of the motor. In the controller, $n_{\text {in }}$ can be set as low as $0.1 \mathrm{rpm}$; thus, theoretically, the minimum speed is $1.28 \times 10^{-3} \mathrm{~mm} / \mathrm{s}$. This value is also the speed resolution of the tensile machine.

TABLE I. Technical parameters of the tensile machine.

\begin{tabular}{ll}
\hline \hline \multicolumn{1}{c}{ Technical parameter } \\
\hline Tensile speed & $1.28 \times 10^{-3} \mathrm{~mm} / \mathrm{s}-102.4 \mathrm{~mm} / \mathrm{s}$ \\
Maximum displacement & $30.0 \mathrm{~mm}$ each side \\
(at $10 \mathrm{~mm}$ of sample length) & 1 -infinite \\
Cycle number & $100 \mathrm{~ms}$-infinite \\
Interval between cycles & $3.0 \mathrm{~mm}$ \\
Maximum specimen thickness & $200 \mathrm{~N}$ \\
Maximum force & $10 \mathrm{~mm}$ \\
Maximum beam size & $36^{\circ}$ \\
Maximum scattering angle & $\pm 10 \mu \mathrm{m}$ \\
Resolution of displacement sensor & $\mathrm{RT}-150^{\circ} \mathrm{C}$ \\
Temperature & $10^{\circ} \mathrm{C} / \mathrm{min}$ \\
Maximum heating rate & $\pm 1^{\circ} \mathrm{C}$ \\
Temperature fluctuation & $550 \times 340 \times 140 \mathrm{~mm}^{3}$ \\
Dimensions & \\
\hline
\end{tabular}

Another important performance is the resolution of displacement. When the output end of the motor rotates one turn, two clamps move $2 l=20 \mathrm{~mm}$. In the encoder, the counts can be calculated by using the following equation:

$$
N=N_{0} \times i,
$$

where $N$ is the total counts and $N_{0}$ is the counts per turn. The theoretical revolution of displacement is given by the following equation:

$$
d_{\text {rev }}=2 l / N \text {. }
$$

Here, $d_{\text {rev }}$ means the revolution of displacement, which is 1.2 $\times 10^{-5} \mathrm{~mm}$. This resolution may be not as high as other commercial machines, while considering that elastomers commonly have large break strain and show no yield, the resolution is still adequate in practical use. The backlash of the gearbox also affects the accuracy of position control. The backlash of the used gearbox is $1^{\circ}$ in average, which corresponds to $0.056 \mathrm{~mm}$ of linear displacement. However, this error is a constant and does not increase cyclic tension. We have tested the machine at a speed of $10 \mathrm{~mm} / \mathrm{s}$ and a displacement of $60.0 \mathrm{~mm}$ for 100 cycles. The change of the SU position read from the displacement sensor is within the error of measurement $( \pm 10 \mu \mathrm{m})$. This shows that the backlash does not induce accumulative error in the position during cyclic tension. Thus, when the backlash is taken into account, the position control can be rather precise.

The tensile force this system can provide is related to the maximum output torque, which is $1.0 \mathrm{Nm}$ for continuous load. The diameter of BSS is $20 \mathrm{~mm}$; thus, with maximum torque, the force along the tangential direction of the screw is $100 \mathrm{~N}$. The provided tensile force can be estimated as follows: the tensile force acts as pressure and the force along the tangential direction of the screw is the corresponding friction. For BSS, the friction coefficient is rather low, e.g., less than 0.01 . Thus, the tensile force can easily exceed the measurement range of the force sensor $(200 \mathrm{~N})$. At this condition, the actual force during tension is determined by the power that the gearbox can output, as shown by the following equation:

$$
F=W / v,
$$

where $F$ is the output force and $W$ is the output power. With highest tensile speed $102.4 \mathrm{~mm} / \mathrm{s}$ and $30 \mathrm{~W}$ power, the output force is $293 \mathrm{~N}$. This is the minimum force that this machine can provide. For elastomers, the typical break strength is well below $50 \mathrm{MPa}$.

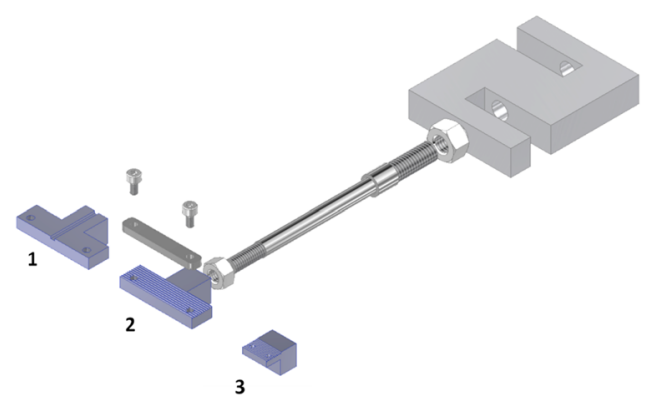

FIG. 2. Dismountable clamp for different sample parameters. 1: fiber clamps, 2: standard clamps (sample width 5-20 mm), and 3: mini clamps (sample width $1-5 \mathrm{~mm})$. 


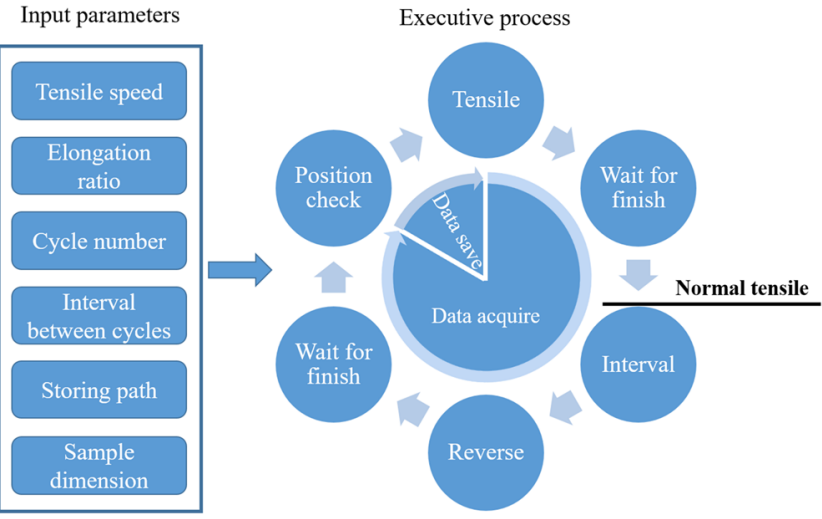

FIG. 3. Flow chart of the experiment process.

Considering a standard dumbbell shape specimen with a width of $2 \mathrm{~mm}$ and thickness of $1 \mathrm{~mm}$, the force at break is $100 \mathrm{~N}$. Clearly, the machine is capable of characterizing the stress-strain relation of most elastomers.

A dismountable clamp is designed, as shown in Fig. 2. In this way, different clamps and tensile sensors can be easily replaced and fixed, depending on different measurement requirements, e.g., stress range and special clamps. Three kinds of clamps are provided in Fig. 2, which are fiber clamps, standard clamps (sample width 5-20 mm), and mini clamps (sample width 1-5 mm), respectively.

\section{The scattering part}

The tensile machine is designed for in situ scattering investigations, including X-ray scattering and neutron scattering. To allow the beam to pass through, two windows are introduced on the heating chamber, as shown in Fig. 1(b). The window for the incident beam has a diameter of $15 \mathrm{~mm}$, slightly larger than the diameter of the incident neutron beam (typically $8 \mathrm{~mm}$ ). The larger diameter of the window has two advantages. First, it is much easier to align the machine on the beamline of small angle neutron scattering. Second, possible scattering from the edge of the window can be avoided. For $\mathrm{X}$-ray, the beam size is commonly less than $1 \mathrm{~mm}$; thus, the window is still large enough in practical use. When designing the scattering

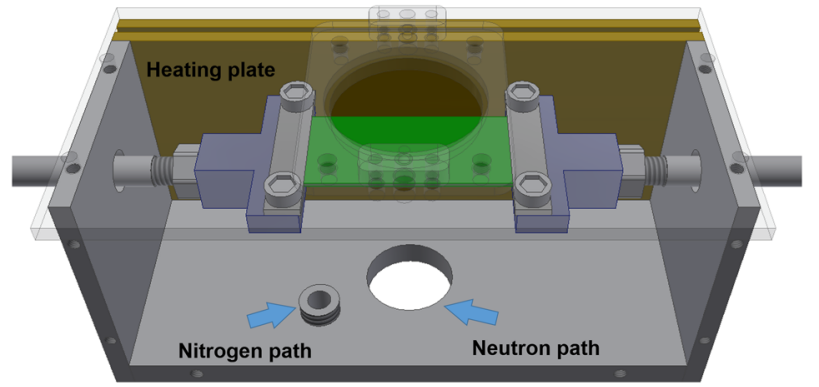

FIG. 4. Internal structure of the heating chamber. The cover and scattering window are set in transparent color for better view.

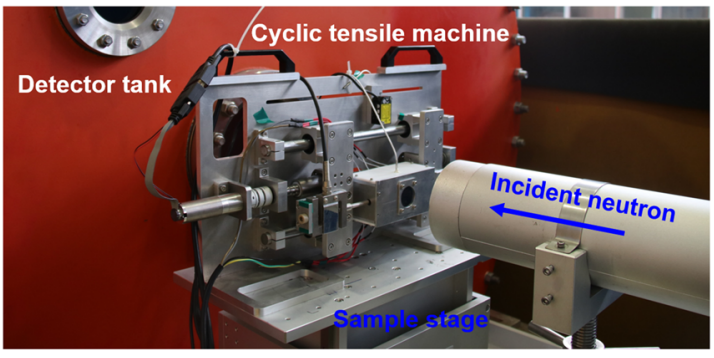

FIG. 5. The cyclic tensile machine installed on the neutron beamline of the spectrometer SANS-Suanni at CMRR.

window, the range of the scattering angle is the major consideration. In small angle scattering measurement, the change in the propagation direction of neutrons or X-rays is within $5^{\circ}$. While for wide angle scattering, which is usually carried out in X-ray scattering, signals above $10^{\circ}$ are monitored. Consequently, the scattering window must be much larger than the incident window. However, the dimension of the heating chamber restricts the size. Considering that for most polymers, scattering appears within the range of $10-30^{\circ}$, the diameter of the scattering window is set as $32 \mathrm{~mm}$. The surface of the specimen is $20 \mathrm{~mm}$ away from the window; thus, theoretically, the scattering signal from the angle of $38^{\circ}$ is still available. Given that the beam may slightly deviate from the center of the window during aligning (e.g., less than $1 \mathrm{~mm}$ ), the actual maximum scattering angle can be $36^{\circ}$.

The window is covered by different materials to prevent uncontrolled thermal convection induced temperature fluctuations. For $\mathrm{X}$-ray scattering, the window is usually covered by the polyimide film, which gives rather weak scattering. Moreover, this film can be used above $200^{\circ} \mathrm{C}$ in long term, ensuring intact window during heating. Artificial sapphire is used when carrying out neutron scattering investigation. The thickness is selected as $1 \mathrm{~mm}$ so that the transmittance of the neutron beam can be kept above 95\%, which is important due to the low flux of the neutron beam. Flanges are installed so that the windows can be easily replaced, as shown in Fig. 1(b).

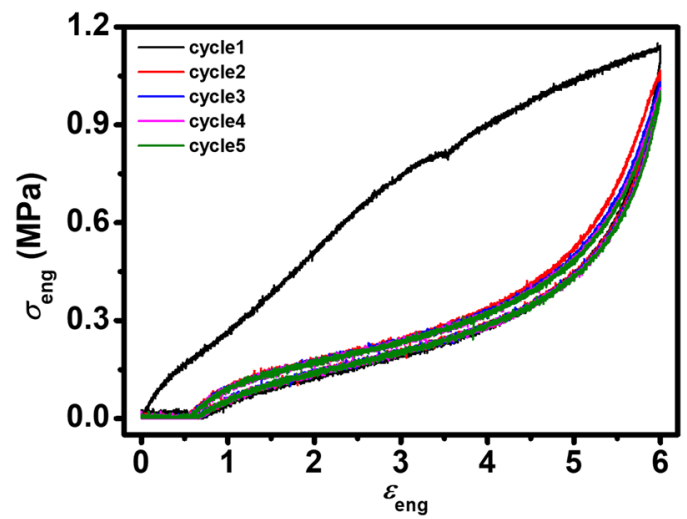

FIG. 6. Engineering stress-strain curve of MWCNT filled silicon rubber during cyclic tension. The tensile speed is $0.1 \mathrm{~mm} / \mathrm{s}$, and the initial length of the sample is $10.0 \mathrm{~mm}$. 


\section{Control system and data acquirement}

In this work, cyclic tension is achieved by program-controlled motor rotation. This method allows continuous change of strain and the strain rate in the limit of speed and position resolution. A flow diagram showing how the machine works is given in Fig. 3. The first part is the input parameters, including tensile speed, elongation ratio, cycle number, interval between cycles, storing path of stress-strain curve, and sample dimension. The special one is the interval between cycles, which may be useful in systems with observable destruction and healing. This parameter is set as $100 \mathrm{~ms}$ for default to avoid errors in communication between the computer and the motor controller and can be set longer for investigation of stress relaxation.

After all the parameters are inputted, cyclic tension can be carried out. In the first cycle, a tensile instruction is sent to the motor controller first and extension starts. Meanwhile, the tensile force from the force sensor and the displacement of SU from the motor controller are recorded. The time needed for finishing the tensile process can be calculated by using the acceleration speed and tensile speed. After the calculated time is reached, the state of the motor will be read periodically (e.g., every 20 milliseconds) by the program until the controller indicates that the tensile process has finished. This is important when the load is high and the acceleration of the motor is markedly slower. Then, the motor will keep its position for a certain time according to the inputted interval. The normal tensile test can be achieved if the interval is set rather large. After the interval, the motor rotates inversely with the same speed as that of the tensile process, and similarly, a loop structure is used to confirm the finish of the movement. Before the second cycle starts, the position of SU2 will be read by the displacement sensor and compared with the initial value. If the error in position is larger than $50 \mu \mathrm{m}$, the position of SU will be corrected first. After this position check, data acquiring stops. The recorded stress-strain curve based on sample dimensions will be saved to the disk according to the selected path. Note that the critical error set in software is slightly larger than the fluctuation of reading from the displacement sensor, which ensures more robust control and still adequately precise tension.

During one cycle, the force and position of SU are read from the force sensor and motor controller continuously, providing the real-time stress and elongation ratio. The acquirement frequency is adjusted according to the tensile speed in the program. Two factors are considered when selecting the frequency. The first one is that
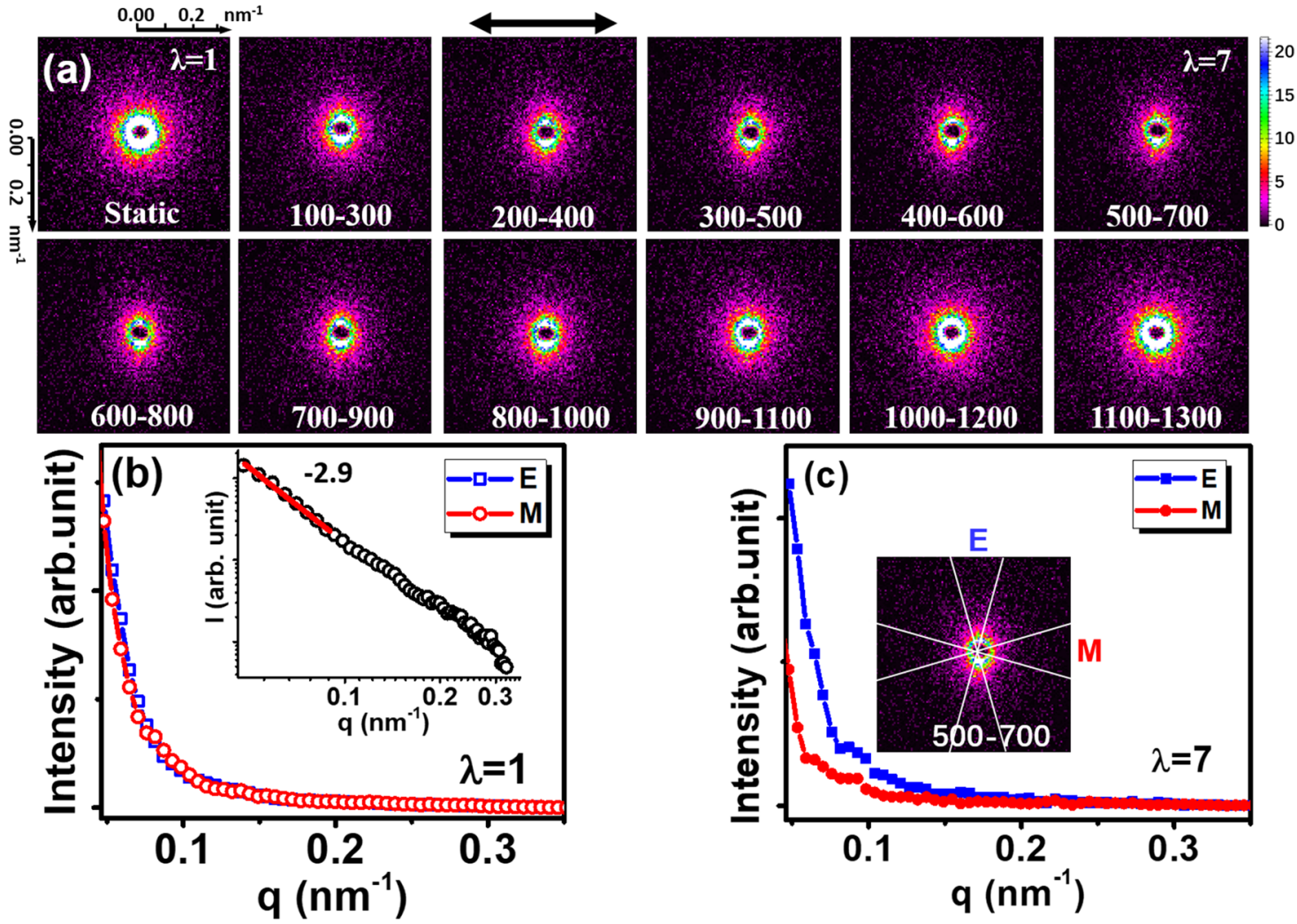

FIG. 7. (a) In situ 2D SANS patterns of the MWCNT/silicone rubber composite during the first tensile process. The numbers in the bottom of each pattern represent experimental time intervals. $q_{\mathrm{x}}, q_{\mathrm{y}}$, and $z$-scale are indicated in the left and right sides, respectively. The stretched direction is horizontal as indicated by the double-headed arrow. The 1D SANS profiles of the sample at an elongation ratio of $\lambda=1$ and $(b)$ and $\lambda=7(c)$, respectively, in both equator $(E)$ and meridian $(M)$ directions. The inset $1 \mathrm{D}$ profiles in (b) show the power-law fitting in a log-log plot. The inset 2D SANS pattern in (c) shows the mask protocol used for integration. 
enough data must be recorded to reproduce the stress response, and the second one is reducing the size of data to make the control more robust. The frequency is set as 10,200 , and $1000 \mathrm{~Hz}$ in this work, depending on the selected tensile speed. Data recorded in one cycle are saved as a separated file, which is convenient to be analyzed and also effectively reduces the file size.

\section{E. Heating system}

The machine can also provide the environment with controlled temperature. A temperature controller (Xiamen Yudian Automation Co., Ltd., China) combined with the heating chamber (as shown in Fig. 4) is used to achieve this function. The controller can set a heating program up to 30 segments with a controlled heating rate. Correspondingly, four ceramic heating plates with a dimension of $40 \times 40 \times 2 \mathrm{~mm}^{3}$ are used to carry out the program. The chamber is constructed using the alloy of aluminum to reduce weight and increase thermal conduction. At the bottom of the chamber, a bipass valve is added to lead nitrogen gas into the chamber, which is used when samples are sensitive to oxygen during heating. With this chamber, samples can be heated to $150^{\circ} \mathrm{C}$ with a maximum heating rate of $10^{\circ} \mathrm{C} / \mathrm{min}$. The overshoot during heating and fluctuation of temperature in the isothermal step is restricted within $1^{\circ} \mathrm{C}$.

\section{SANS INVESTIGATION DURING CYCLIC TENSILE TEST OF SILICON RUBBER}

The apparatus for the in situ SANS study on tension of carbon nanotube filled silicon rubber is tested on a SANS-Suanni spectrometer at CMRR. Figure 5 depicts the cyclic tensile machine installed on the neutron beamline.

The silicon rubber used is a two-component addition-type rubber. The multiwall carbon nanotube (MWCNT) has been purchased from XFNano (China), which has a length of $10-30 \mu \mathrm{m}$ and a diameter of $2-10 \mathrm{~nm}$. The surface is modified by the hydroxyl group. Dur-

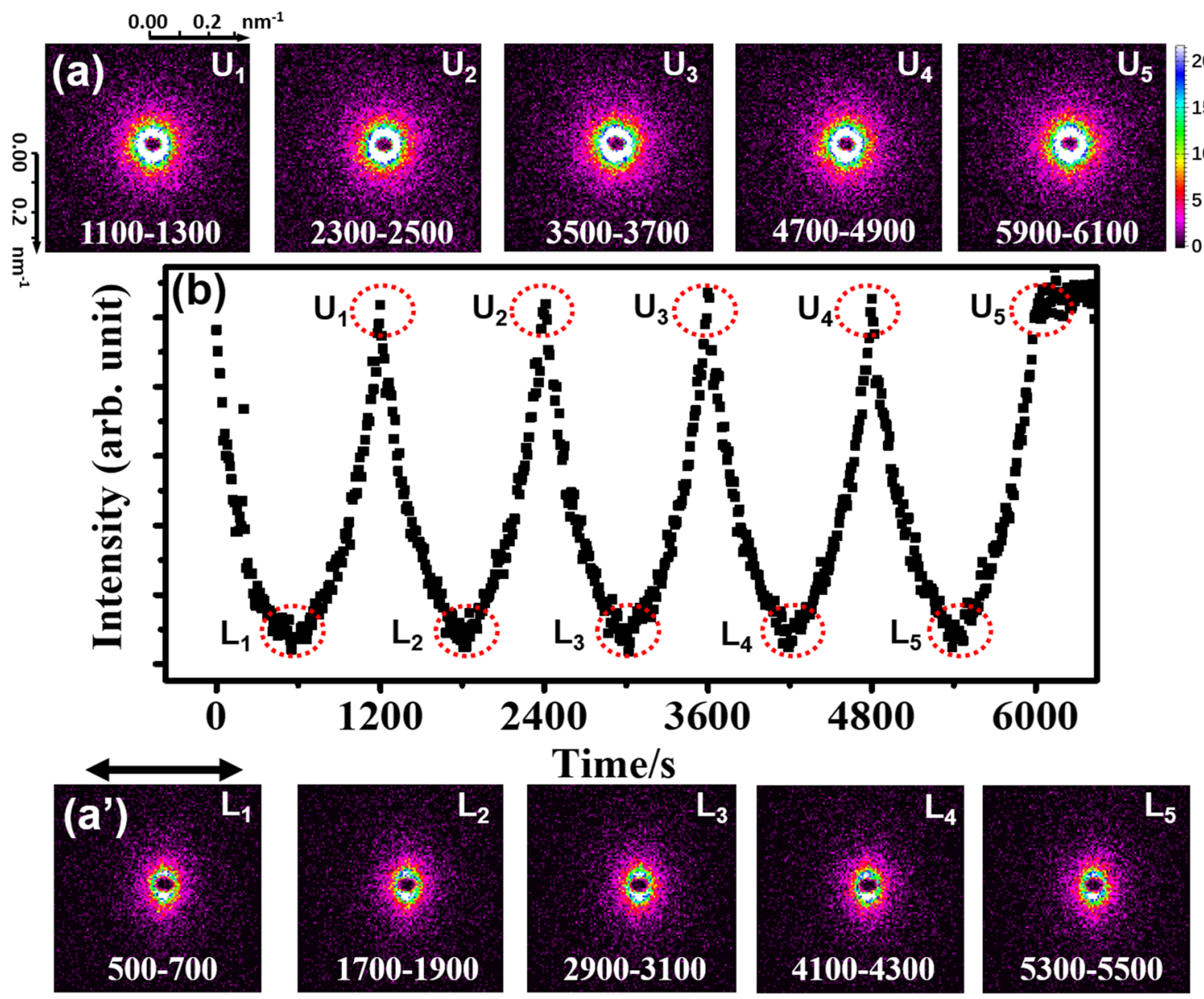

FIG. 8. In situ 2D SANS patterns of the MWCNT/silicone rubber composite during loading (L) at around maximum strain (a) and unloading (U) states ( $\left.\mathrm{a}^{\prime}\right)$ of cyclic tension. The subscripts in the top right corners indicate the numbers of cycles. The numbers at the bottom of each pattern represent experimental time intervals. (b) Intensity as a function of time. Intensity is the total detector counts recorded and acquired at a rate of $10 \mathrm{~s} /$ point. The red-dotted circles indicate the time intervals for the corresponding $2 \mathrm{D}$ SANS patterns. 
ing mixing, component $\mathrm{A}$ of silicon rubber, toluene, and MWCNTs were first stirred for one day. After that, component B of silicon rubber was added and stirred for $1 \mathrm{~h}$. Then, toluene was removed by rotary evaporation at $40-50{ }^{\circ} \mathrm{C}$ for $10 \mathrm{~min}$. The mixture was put between two glass plates as a sandwich during crosslinking. Crosslinking was carried out at room temperature for two days and then at $100^{\circ} \mathrm{C}$ for $2 \mathrm{~h}$. The obtained film has a thickness of $370 \mu \mathrm{m}$. In the tensile test, the film was cut into a rectangular shape with a width of $10 \mathrm{~mm}$.

The first example is the in situ investigation of alignment of MWCNTs in a silicone rubber matrix during five cycles of the loading-unloading process. Stress was recorded continuously during extensions with the force sensor. The engineering stress-strain curve of the composite in Fig. 6 shows the mechanical response during the deformation. In the first tensile process, the stress increases with strain continuously. Several changes in the slope of stress increase can be found, which should be related to structural changes during tension of the composite. When the deformation is released, a large hysteresis is found. This is known as the Mullins effect. ${ }^{46,47}$ Besides the decrease of stress, a permanent deformation around 0.5 is also observed. In the subsequent cycles, the stress-strain curve becomes smooth and the hysteresis is much lower. A slight decrease in stress can be still found when more cycles are conducted, while the permanent deformation seems to change little. The behaviors are rather similar to those found in filled natural rubber. ${ }^{10}$

The corresponding structure evolution was monitored by in situ two-dimensional (2D) SANS measurement with the spectrometer SANS-Suanni at CMRR. The wavelength of the incident neutron is $0.53 \mathrm{~nm}$, and the sample-to-detector distance is $11 \mathrm{~m}$, giving a $q$ range as $\sim 0.05$ to $0.35 \mathrm{~nm}^{-1}$. The stretched direction (SD) is horizontal, as indicated by the double-headed arrow. Figure 7(a) significantly shows different features of 2D SANS patterns with different strains in the first tensile process. The 2D SANS pattern of the unstretched composite is isotropic. For the loading process, a clear anisotropic signal perpendicular to the tensile direction shows up while increasing the elongation ratio, and the orientation increases with strain. During the unloading process, the extent of the anisotropic signal becomes weaker and finally vanishes. The difference between the unstretched sample $(\lambda=1$, static) and the stretched sample ( $\lambda=7$, time range from $500 \mathrm{~s}$ to $700 \mathrm{~s})$ are clearly shown in 1D SANS profiles integrated in both equator and meridian sectors, as indicated in Figs. 7(b) and 7(c). The power-law fitting with a form as $I=A q^{\alpha}+I_{\mathrm{bkg}}$ in the log-log plot on the static profile is presented in Fig. 7(b) as an inset. The value of $\alpha$ in the $q$ range of $0.05-0.09 \mathrm{~nm}^{-1}$ is 2.9 , suggesting a mass fractal distribution character. This might be attributed to the aggregation of the MWCNTs in the silicone rubber matrix.

Changes of 2D SANS patterns of MWCNTs/silicone rubber composite during five cycles of loading (L) and unloading (U) are presented in Figs. 8(a) and 8( $\left.\mathrm{a}^{\prime}\right)$, respectively. In each cycle, the loading and unloading processes result in a decrease and increase in scattering intensity as a function of time, as indicated in Fig. 8(b), corresponding well to the cyclic thickness change. Meanwhile, 2D patterns show stronger scattering along the vertical direction at around the maximum strain (e.g., $500 \mathrm{~s}-700 \mathrm{~s}$ ) and nearly isotropic scattering after unloading (e.g., $1100 \mathrm{~s}-1300 \mathrm{~s}$ ). It is also interesting to see that the scattering pattern is rather similar in the first and second cycles, even though the stress response changes significantly.
In this work, scattering comes from MWCNTs only; thus, a similar scattering pattern that indicates hysteresis mainly comes from the structural change at the segment scale, e.g., breakage of chemical bonds at regions with inhomogeneous crosslinking density, but not a different deformation state of MWCNTs.

The above examples demonstrate the flexibility of the current cyclic tensile machine and necessity of combining in situ scattering investigation. Variant experimental conditions are available by using this machine, such as cyclic tensile test, common uniaxial tension, and stress relaxation measurement, which can be easily combined with either X-ray scattering or neutron scattering.

\section{CONCLUSION}

In this work, a tensile machine for the cyclic tensile test and the in situ scattering study of elastomers is designed. The machine is driven by using a servo motor, and two clamps move oppositely during the loading-unloading process. With this configuration, in situ scattering measurement can be easily conducted. A heating chamber is added to control the environmental temperature. When using different windows (i.e., Kapton film or sapphire), either X-ray scattering or neutron scattering can be carried out. The stress-strain curve during cyclic tension is recorded spontaneously when each cycle finishes. Moreover, an independent displacement sensor is used to monitor the possible accumulative error in position after each cycle. This machine is tested by investigating the orientation of MWCNTs mixed in silicon rubber with in situ SANS. It is found that the stressstrain curve shows large hysteresis in the first cycle and changes relatively little in the subsequent four cycles. Meanwhile, the orientation of MWCNTs increases with strain and vanishes when strain is released, showing good reversibility. These results give a successful demo of this machine.

\section{ACKNOWLEDGMENTS}

Financial support from the National Natural Science Foundation of China (Grant Nos. 21504069 and 11605171) is acknowledged. N.T. also thanks the support of "the Fundamental Research Funds for the Central Universities" of Northwestern Polytechnical University (Grant No. 310201911cx011) and support of "the Opening Foundation of National Center for International Research of Micro-nano Molding Technology \& Key Laboratory for Micro Molding Technology of Henan Province" (Grant No. MMT201606). D.L. thanks the support of the National Key Research and Development Program of China (Grant No. 2018YFB0704200) and the Foundation of President of CAEP (Grant No. YZJJLX2018004).

\section{REFERENCES}

${ }^{1}$ S. Trabelsi, P.-A. Albouy, and J. Rault, Macromolecules 35, 10054 (2002).

${ }^{2}$ J. Rault, J. Marchal, P. Judeinstein, and P. Albouy, Macromolecules 39, 8356 (2006).

${ }^{3}$ Q. Chen, L. Zhu, L. Huang, H. Chen, K. Xu, Y. Tan, P. Wang, and J. Zheng, Macromolecules 47, 2140 (2014).

${ }^{4}$ X. Wang and W. Hong, Soft Matter 7, 8576 (2011).

${ }^{\mathbf{5}}$ E. Ducrot, Y. Chen, M. Bulters, R. P. Sijbesma, and C. Creton, Science 344, 186 (2014).

${ }^{6}$ J.-Y. Sun, X. Zhao, W. R. Illeperuma, O. Chaudhuri, K. H. Oh, D. J. Mooney, J. J. Vlassak, and Z. Suo, Nature 489, 133 (2012). 
${ }^{7}$ J. P. Gong, Y. Katsuyama, T. Kurokawa, and Y. Osada, Adv. Mater. 15, 1155 (2003).

${ }^{8}$ R. E. Webber, C. Creton, H. R. Brown, and J. P. Gong, Macromolecules 40, 2919 (2007).

${ }^{9}$ T. Nakajima, T. Kurokawa, S. Ahmed, W.-1. Wu, and J. P. Gong, Soft Matter 9 , 1955 (2013).

${ }^{10}$ M. Brieu, J. Diani, C. Mignot, and C. Moriceau, Int. J. Fatigue 32, 1921 (2010).

${ }^{11}$ K. K. Kar and A. K. Bhowmick Polym, Eng. Sci. 38, 38 (1998).

${ }^{12}$ M. S. H. Fatt and X. Ouyang, Mech. Mater. 40, 1 (2008).

${ }^{13}$ H. Pouriayevali, Y. Guo, and V. Shim, Int. J. Impact Eng. 47, 71 (2012).

${ }^{14}$ J. Ju, F. Su, Z. Wang, H. Yang, X. Tang, X. Chen, Y. Lv, J. Lu, N. Tian, and L. Li, Polymer 131, 68 (2017).

${ }^{15}$ M. Cheng and W. N. Chen, Int. J. Solids Struct. 40, 2249 (2003).

${ }^{16}$ C.-W. Chang, A. van Spreeuwel, C. Zhang, and S. Varghese, Soft Matter 6, 5157 (2010).

${ }^{17}$ L. Huang, C. Li, W. Yuan, and G. Shi, Nanoscale 5, 3780 (2013).

${ }^{18}$ J. D. Londono, R. V. Davidson, D. Brill, D. H. Roach, R. A. Leach, and J. P. Quintana, J. Appl. Crystallogr. 33, 704 (2000).

${ }^{19}$ H. Guo, J. Wang, C. Zhou, W. Zhang, Z. Wang, B. Xu, J. Li, Y. Shang, J. de Claville Christiansen, and D. Yu, Polymer 70, 109 (2015).

${ }^{20}$ Z. Xiong, G. Liu, X. Zhang, T. Wen, S. de Vos, C. Joziasse, and D. Wang, Polymer 54, 964 (2013).

${ }^{21}$ E. Straube, V. Urban, W. Pyckhouthintzen, D. Richter, and C. J. Glinka, Phys. Rev. Lett. 74, 4464 (1995).

${ }^{22}$ D. Liu, J. Chen, L. X. Song, A. Lu, Y. L. Wang, and G. G. Sun, Polymer 120, 155 (2017).

${ }^{23}$ A. Botti, W. Pyckhout-Hintzen, D. Richter, V. Urban, E. Straube, and J. Kohlbrecher, Polymer 44, 7505 (2003).

${ }^{24}$ A. S. Robbes, F. Cousin, and F. Meneau, J. Jestin, Macromolecules 51, 2216 (2018).

${ }^{25}$ D. Valladares, S. Toki, T. Z. Sen, B. Yalcin, and M. Cakmak, Macromol. Symp. 185, 149 (2002).

${ }^{26}$ D. Valladares, B. Yalcin, and M. Cakmak, Macromolecules 38, 9229 (2005).

${ }^{27}$ O. Yucel, E. Unsal, J. Harvey, M. Graham, D. H. Jones, and M. Cakmak, Polymer 55, 4091 (2014).
${ }^{28}$ S. Seif and M. Cakmak, Polymer 51, 3762 (2010)

${ }^{29}$ Y. R. Liang, Y. J. Tan, Y. H. Guo, M. Z. Hao, T. Zhang, L. Y. Wang, Z. Mutlu, and M. Cakmak, Polymer 169, 52 (2019).

${ }^{30}$ Z. H. Hong, Y. H. Cong, Z. M. Qi, H. L. Li, W. M. Zhou, W. Chen, X. Wang, Y. G. Zhou, and L. B. Li, Polymer 53, 640 (2012).

${ }^{31}$ L. P. Meng, Y. F. Lin, J. L. Xu, X. W. Chen, X. Y. Li, Q. L. Zhang, R. Zhang, N. Tian, and L. B. Li, Chin. J. Polym. Sci. 33, 754 (2015).

${ }^{32}$ N. Tian, W. Q. Zhou, K. P. Cui, Y. P. Liu, Y. Y. Fang, X. Wang, L. B. Liu, and L. B. Li, Macromolecules 44, 7704 (2011).

${ }^{33}$ Y. P. Liu, W. Q. Zhou, K. P. Cui, N. Tian, X. Wang, L. B. Liu, L. B. Li, and Y. G. Zhou, Rev. Sci. Instrum. 82, 045104 (2011).

${ }^{34}$ B. J. Zhao, N. Tian, Y. P. Liu, T. Z. Yan, W. Q. Zhou, L. B. Li, Y. G. Zhou, G. S. Weng, and G. S. Huang, J. Polym. Sci., Part B: Polym. Phys. 50, 1630 (2012). ${ }^{35}$ J. Zhao, R. Yang, R. Iervolino, and S. Barbera, J. Appl. Polym. Sci. 132, 41319 (2015).

${ }^{36}$ D. Kroll and S. Croll, Polymer 79, 82 (2015).

${ }^{37}$ I. Kaneda and S. Iwasaki Rheologica, Acta 54, 437 (2015).

${ }^{38}$ Y. Numata, K. Muromoto, H. Furukawa, J. P. Gong, K. Tajima, and M. Munekata, Polym. J. 41, 524 (2009).

${ }^{39}$ M. Mohtadi-Bonab, M. Eskandari, H. Ghaednia, and S. Das, J. Mater. Eng. Perform. 25, 4933 (2016).

${ }^{40}$ E. Yang, Z. Xu, M. Baniasadi, S. Moreno, H. Yi, J. Di, R. Baughman, and M. Minary-Jolandan, J. Mater. Sci. 53, 11426 (2018).

${ }^{41}$ S. Weigand, B. Stillwell, W. E. Guise, J. P. G. Quintana, and D. T. Keane, Adv. X-Ray Anal. 52, 58-68 (2009).

${ }^{42}$ M. Peng, L. Sun, L. Chen, G. Sun, B. Chen, C. Xie, Q. Xia, G. Yan, Q. Tian, and C. Huang, Nucl. Instrum. Methods Phys. Res., Sect. A 810, 63 (2016).

${ }^{43}$ L. Chen, L. Sun, Q. Tian, T. Wang, J. Chen, G. Sun, C. Huang, and D. Liu, J. Instrum. 13, P08025 (2018).

${ }^{44}$ Q. Tian, G. Yan, L. Bai, J. Chen, D. Liu, L. Chen, L. Sun, C. Huang, B. Chen, and G. Nagy, J. Appl. Crystallogr. 51, 1662 (2018).

${ }^{45}$ G. Sun, C. Zhang, B. Chen, J. Gong, and S. Peng, Neutron News 27, 21 (2016).

${ }^{46}$ J. Diani, B. Fayolle, and P. Gilormini, Eur. Polym. J. 45, 21 (2009).

${ }^{47}$ J. M. Clough, C. Creton, S. L. Craig, and R. P. Sijbesma, Adv. Funct. Mater. 26, 9063 (2016). 